\title{
CUNQUEIRO NO GRIAL
}

\section{Manuel Outeiriño}

Universidade de Santiago de Compostela doi:10.17075/mucnoc.2014.029

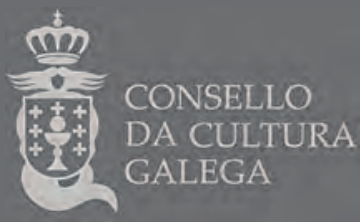



Forcadela, M. / T. López / D. Vilavedra (coords.) (2014): Mil e un cunqueiros. Novas olladas para un centenario, Santiago de Compostela, Consello da Cultura Galega. doi:10.17075/mucnoc.2014. pp. 575-586

O de Cunqueiro en Grial foi xornalismo bo e xeneroso. Bo pola calidade do que escribiu para a revista galeguista e xeneroso porque non se lucrou nada deses artigos. Cunqueiro foi gran xornalista, pois soubo modular o seu estilo segundo escribía para o público xeral do Faro de Vigo, para o público máis reducido doutras revistas ou para o público ilustre de Grial .

Ben é certo que Cunqueiro fixo propaganda fascista, do que deron mostra sabiamente Río Conde (1993) e antes Brea e Folgar (1982). Porén, quero crer, con argumentos próximos aos expostos por Ana María Spitzmesser ${ }^{2}$, que o subconsciente político de Cunqueiro empezou a resistirse ao fascismo pola metade dos cincuenta. Tal é a razón da súa reacción fantasiosa perante a realidade represiva establecida a sangue e ferro na posguerra. Coido que hai no fabular desartellado e caótico —ou «caósmico», para o dicir con palabras Deleuze e Guattari (1980)— de Cunqueiro, gran desdobramento de angustia que se explica por razóns históricas e políticas. O seu proceso de reacción e formación é, no meu ver, o dunha psique que tenta sobrevivir á catástrofe do fascismo, á que nun primeiro momento se adaptara moi cinicamente o eu consciente con triste afán de supervivencia. Verbo disto falou tamén Pérez-Bustamante 3 .

1 Sobre os artigos de Cunqueiro, dicía Freixanes (1991: 24): «A técnica do artigo case sempre é a mesma: un suceso, a noticia-pretexto, e da man da noticia, o miragre; viaxe maravillosa coa imaxinación desatada, ceibe, prodixiosa, chea de referencias cultas e intuicións fascinadoras». Coido que a apreciación de Freixanes é errónea. A variedade de xéneros e estilos xornalísticos que cultivou Cunqueiro foi grande. Pode advertirse mesmo nas colaboracións publicadas no Grial.

2 Spitzmesser (1996: 29): «No es aventurado afirmar entonces que la narrativa de Cunqueiro cumple, en oposición a lo que se ha afirmado, una función a su manera testimonial sobre la condición humana bajo la dictadura, subvirtiendo los mitos oficiales y la necesidad humana de dichos mitos a través de la ironía y la parodia y cuestionando la complacencia del lector con la falsa "normalidad" de lo cotidiano".

3 Dicía Pérez-Bustamante (1991: 28): «comprendemos como, através de las experiencias que van desde los años de la II República hasta la década de los 50, etapa decisiva, se fragua en Cunqueiro la más auténtica y vital rebelión metafísica que le va a llevar a la narrativa en una conjunción de defensa de su propio ser y del ser de Galicia, en una conjunción del pensamiento arcaico y el pensamiento simbolista y surrealista en lo que éste comparte con la filosofía romántica alemana».

Alén da cuestión da «rebelión metafísica», Pérez Bustamante indicou que a arte narrativa de Cunqueiro foi unha forma de fuxida. Dicía Pérez-Bustamante (1991: 29): «No huyó Cunqueiro por la poesía, aunque nunca dejara de escribirla, sino fundamentalmente a través del relato, y no empezó a relatar más que a 
O seu probado amigo Joan Perucho (1994: 31-32), na achega ao número que dedicou a Cunqueiro o boletín da Fundación García Lorca, dixo que Cunqueiro «escamotea a realidade deste mundo». Spitzmesser (1996: 26) indicou que no fabular de Cunqueiro está a «aceptación da castración» e a negación do desexo. Isto é ben triste e interesante: a negación do desexo-revolución, que diría o Jean-François Lyotard (1973).

Ferrín indicou, no anterior congreso sobre o autor de Merlín e Familia (AA. VV., 1993), que Cunqueiro foi reaccionario na prensa até a fin dos deus días. Carlos Casares (AA. VV., 1993: 231), no mesmo Congreso, dixo: «entre Cunqueiro e a realidade histórica ou realidade social había sempre algo que se interpuña. En concreto, o que se interpuña era a literatura».

Ao rego de Carlos Casares, coido que no xornalismo de Cunqueiro se manifestou decote o problema de interpretar a realidade a xeito de texto, o problema das análises textualistas da cultura e da sociedade, do que falou criticamente Terry Eagleton (2004) no libro After Theory. Este é, ao cabo, o problema Cunqueiro que, no meu ver, puido autorretratarse no artigo «Un gaiteiro", publicado no no 28 da revista Grial. É posible pensar que ao falar das historias que lle gustaría contar musicalmente ao gaiteiro Ramón de Crecente Cunqueiro estivese a se autorretratar. Velaí o que dicía o autor das Crónicas do Sochantre:

Nas parrafadas que [...] temos botado [...] gustáballe dicir que si soupera solfa, iba pońer en música todo, "todo o que pasa". Pero o que pasaba, pra el, non eran mesmamente os sucedos do mundo, sinón o ritmo cheo e total da vida, a sementeira e a colleita, o vento e achuvia, os ríos e as mozas, as nubes e os paxaros, as fontes e o lume do fogar, o amor e as catro estacións, o viño e a ausencia. Todo o demáis é política.

No inicio dese mesmo artigo, Cunqueiro incluíu esta consideración sobre a escritura, o pracer e o viño, quizais tamén sobre a relación entre ebriedade e literatura:

Non se escandalicen, que eu non iba á taberna a botar un trago. Xa teño contado que iba a me pońer en contas: sentábame coa mińa pizarra ao pé do bocoi de Valdeorras, a carón da fiestra, e púńame toda unha longa tarde a pescudar, si cinco pipas tran tantos litros, cantos traguerán dezasete.

partir de 1939. Recoredemos entonces que M. Eliade expone que es sobre todo a través de la narrativa, con su creación de universos imaginarios, como el hombre contemporáneo se rebela contra dimensión histórica y accede al tiempo mítico». 
Tamén hei contar os meus pecados: estando tan perto a cunca da pinguela, baixo a billa de buxo de Monterroso, adoitaba mollar o pizarrillo nela e despois chupalo. Xa teño dito que foi o primeiro viño que catei.

Algo de verdade hai neste artigo. Polo menos, cómpre lembrar que o detalle do pizarrillo co que catou o primeiro viño volveu contarllo a Carlos Casares nunha das últimas entrevistas que concedeu ${ }^{4}$.

\section{A REVISTA GRIAL}

No Grial están algúns dos artigos máis sinceros de Cunqueiro. A evocación «Seoane, o meu ilustador», escrita para o número de homenaxe ao pintor, lembra a xénese do seu primeiro libro de poemas, Mar ao Norde (1932) e o apoio crucial do que logo sería autor de Fardel de Eisiliado.

Son tamén celmosas, sinxelas e sinceras (desprovistas do artificio que usou decote nos célebres artigos do Faro) as lembranzas do Manuel Colmeiro estudante a comprar mazás na praza de Fonseca e indo lavalas á fonte de Praterías (Grial, no 51). O Cunqueiro sincero de artigos como «Seoane, o meu ilustrador», ou «Manuel Colmeiro» (Grial 1976, pp. 84-86) é tamén o que sabe amosar sinxeleza, sana simplicitas, no poema "Chove» (Cunqueiro 2011, p. 187), onde o lector recońecerá un tópico idealista que o mindoniense adubou de brillantez retórica noutros poemas máis coñecidos, poño por caso «O poeta esquece os días de chuvia».

No no 70 de Grial en 1978 (pp. 204-207), editouse o prólogo de «Xan o bo conspirador. Invención nun prólogo e dous actos». Indicábase que o texto aparecera entre papeis de Manuel Colmeiro. A escena inicial de "Xan, o bo conspirador», que cómpre engadir aos proxectos inacabados de Cunqueiro, editárase na Rexión, de Ourense, en 1993. No prólogo de «Xan, o bo conspirador» son «As cinco. A mesma hora de sempre» e os personaxes son tres: o home da gravata, o home sen gravata e a nena da fiestra. Ningún destes personaxes aparece na escena final, publicada o 14 do Santiago do 1933 na rexión.

Tamén é importante o texto "Comezando por un morto» (Grial 1973), adianto do que ía ser a novela El año del cometa. Pertinente e de carácter histórico é o artigo

4 Carlos Casares, «Leria con Álvaro Cunqueiro», Grial, n 72, pp. 202-209. 
sobre Ramón Cabanillas (Grial, no 59) no que presta especial atención aos seus inicios poéticos.

Hai dous artigos interesantes dos anos 1968 e 1972, escritos co pseudónimo S. S., sobre a actualidade da cultura occitana, que probablemente ollou con excesivo optimismo, mais con agarimo xustificado 5 .

A nota sobre Esopo en galego (1967) ofrécenos magníficas reflexións sobre a fábula. Crucial tamén é o que escribiu sobre Dickens co pseudónimo de Patricio Mor. O artigo sobre o Marcel Proust de G. D. Painter, asinado tamén co pseudónimo Patricio Mor, amosa apreciacións finas sobre a tradución e ten indicacións tan pertinentes como esta: «A obra de Proust constitúe un exemplo da distinción formulada por Wordsworth entre fantasía e imaxinación, é decir, entre a arte que inventa o que endexamáis existiu i a arte que descobre o significado interno do que xa existe. Somos libres —e nisto Painter aparez como un goetheano- de considerar que a maxinación é superior á pantasía, pro nunca podemos decir que é inferior».

Quizais vallan tamén estas palabras para amosar que foi Cunqueiro un grande escritor imaxinativo máis que fantasioso. Esta distinción entre imaxinación e fantasía é ao que, ao cabo, indica o título da sección que mantivo moitos anos no Faro de Vigo: $O$ envés. Sobre $O$ envés dicíalle en 1981 a César Antonio Molina: «Tengo siempre una tendencia, incluso en los momentos sentimentales o emocionales más hondos, irónica, a verle a la vida su otro lado, el envés ${ }^{6}$. Esta tendencia é un dos aspectos máis interesantes do xornalista gaiteiro, que podería ser un pouco como o gaiteiro enterrador da novela Os libros arden mal de Manuel Rivas.

Cunqueiro traduciu no Grial autores galardoados co Nobel, poño por caso Kabawata ou Nelly Sachs. Abofé que na tradución baixo pseudónimo de Sachs é proba da autoría de Cunqueiro a forma verbal do verso «ben antes de que se salvesen os nosos corpos», propia do dialecto mindoniense.

5 Os textos sobre $O$ renacemento das letras occitanas publicados en Grial $(1968,1972)$, moi políticos e ben intencionados, aínda que non moi celmosos, parecen resumos de prensa parisiense. Sorprende a consideración política e programática sobre a importancia das emisións televisivas, aínda que Cunqueiro falaba do beneficiosa que podía ser a emisión de só un ou dous programas mensuais. Esta consideración é todo un síntoma de que Cunqueiro asumía, como hoxe fan aínda máis lamentablemente moitos, o atraso progresivo do uso público da lingua. En todo caso, foi Antonio Odriozola quen atribuíu a autoría destes textos a Cunqueiro.

6 Molina (1994: 170). 
No Grial no 57 (1977, p. 371) publicouse "Cómo hai que ler a Kafka», que é, nomeadamente, recensión de Franz Kafka, por unha literatura menor, de Gilles Deleuze. O artigo, asinado S. S., incluíuno Antonio Odriozola na bibliografía de Cunqueiro. No artigo «Sobre a sombra de Rosalía de Castro» (1977), Cunqueiro comenta un traballo de Agustín García Calvo publicado en La Gaya Ciencia. Convida a lelo gabando a «singular finura» do autor de Sermón de Ser y no Ser. ${ }^{7}$ Co pseudónimo Álvaro Labrada (1968, pp. 486-7) escribiu sobre o Graal con precisión e coñecemento da historia literaria. Este artigo é máis un exemplo de que Cunqueiro modulaba de xeito distinto os artigos segundo escribise para o público xeral ou para públicos máis restrinxidos.

Sexa como for, hai máis textos de Cunqueiro no Grial dos indicados por Odriozola e algúns ben poden ser recensións anónimas. Por que non ha ser de Cunqueiro o anónimo Un libro de mitoloxía celta, recensión breve e celmosa de Celtic Mythology de Proinsias MacCana (Grial, 1970, p. 376)?

O Cunqueiro do Grial foi parcialmente editado no tomo Iv das obras completas. As tales obras completas detivéronse nese tomo IV. Porén, coido que moitos lectores han agradecer un tomo de Cunqueiro no Grial.

\section{O XORNALISMO LITERARIO DE CUNQUEIRO}

Alén de moitas celmosas achegas ao Grial, boa mostra do xornalismo literario de Cunqueiro son os artigos de «El noticiero universal» recompilados no libro Papeles que fueron vidas. No artigo "Arte verbal y estructura social» (1974), Cunqueiro (1994: 84), comentando o libro homónimo de Carmelo Lisón Tolosana, expón o que eran as «loias» ou regueifas. Tamén é importante o artigo "Paul Eluard en Compostela» (Cunqueiro 1994: 165-167) (10-XII-1974), pois expón reflexións sobre o surrealismo na poesía galega de preguerra. Cómpre lembrar o que se di n’ $A$ rosa pública (1934) de Paul Éluard sobre a obxectividade poética:

A obxectividade poética

7 Cunqueiro xa publicara o 22 do Santiago do 1975 en El noticiero universal un comentario gabancioso do ensaio de García Calvo (Cunqueiro, 1994: 250-253). De por parte, no ano 1971, publicara o poema «Na outra habitación, trala outra porta» (Cunqueiro, 2011: 215-6), onde tamén aparece o tópico da sombra en Rosalía. 
Non existe máis ca na sucesión, no encadeamento de elementos subxectivos todos dos que o poeta é, ata nova orde, non o mestre, mais o escravo.

Quizais boa parte do xornalismo de Cunqueiro foi escravo convicto destes encadeamentos da obxectividade poética. De por parte, André Breton, no Segundo manifesto do surrealismo, escribiu: «a vida e a mente, o real e o imaxinario, o pasado e o futuro, o comunicable e o incomunicable, o alto e o baixo, deixan de se percibir contraditoriamente». Esta característica do surrealismo, relacionada coa «obxectividade poética», paréceme tamén frecuente no xornalismo do Cunqueiro que, no meu ver, puido autorretratarse no texto "Un gaiteiro».

No artigo "Poeta en altos montes Cunqueiro» (1994: 178-181) comentou a saída d'Os eidos-2 de Uxío Novoneyra. É pertinente a distinción que fixo entre os usos singular e plural da palabra eido. Remata este artigo dicindo: «Debía haber unha tinta feita con terra, vento e saudade pra que Teixeira, Noriega e Novnoneyra escribisen os seus poemas. Unha tinta cincenta».

No artigo «Los días de las floridas» (Cunqueiro 1994: 205) falou das viaxes de Bran, sobre o que escribiu quizais naquel mesmo momento o poema inicial de Herba aqui e acolá. Pleito por unha illa refírese á disputa pola posesión da illa de San Simón entre os concellos de Vigo e Redondela (Cunqueiro 1994: 207-210) e remata falando "dunha lingua, dunha nación, dunha certa idea sentimental, da memoria amorosa dos galegos». No artigo "Xéneros literarios» (Cunqueiro 1994: 124) propón, con humor, que se categoricen novos xéneros. Fala do xénero que constituirían os discursos dos dragóns e de que lle gustaría meterse dentro da Coca de Redondela e facer o discurso do dragón. No artigo "As palabras salvaxes» menciona dúas que teñen moito miolo: mercantil-lyrisme e cosmopolisson.

Ora ben, houbo outro Cunqueiro xornalista de oficio que non se ocupou de materias nobres, aínda que nunca perdese a graza. Véxase, poño por caso, o artigo "A saia da Carolina» para a revista Bazaar, recompilado no libro La bella del Dragón (Cunqueiro, 1991: 185-187). É unha fábula erótica na que dicía «Teño un amigo en Ourense do que o avó visitou o leito de Carolina...». Este artigo é un dos moitos que amosan unha das características máis cońecidas do xornalismo de Cunqueiro: o humor popular. 


\section{HUMOR POPULAR}

O humor popular das historias que escribía nos xornais amosouse nos libros Xente de aqui e de acolá (1971) e Os outros feirantes (1979) ${ }^{8}$. No limiar de Xente de aqui e de acolá (1971), referíndose ás características dos tipos galegos, fala da «ironía que fai dun home, nun intre dado, un señor rei». Tal potencia da ironía é quizais definitoria da actitude literaria de Cunqueiro.

Paga a pena lembrar algunhas historias humorísticas que publicaba na prensa o mindoniense. Felipe de Burres trata con doce ironía do «progreso das telecomunicacións» (Xente de aqui e de acolá, p. 90). Tristán García (Os outros feirantes, p. 117) válese da tópica do mundo literario en contraste coa realidade: é unha fábula moral moi emotiva dun tempo xa distante coa que pechou tamén as versións casteláns levemente modificadas que son Las historias gallegas. Na descrición biográfica d'Unha siria de Ribadeo (Os outros feirantes, p. 29) o narrador declara inventar costumes de vilas por mor de entreter os interesados nos seus relatos.

O limiar de Las historias gallegas de D. Álvaro Cunqueiro (que se leran por radio e son, nomeadamente, tradución castelá — con licenzas, pequenas supresións e pequenos engadidos - d'Os outros feirantes) amosa, na altura de hoxe, unha concepción tanto esencialista como exótica dos galegos ou do pobo galego, expresión que Cunqueiro usaba, aínda que nestes días non me ten dúbida que fará alporizar a moitos politólogos e xente de servir. No falar do pobo galego ou dos moitos galegos que escolle a xeito de mostras, Cunqueiro amósanos caracterizados polas crenzas máxicas e as supersticións. É, no meu ver, moi mal favor fainos. Segundo Cunqueiro, o galego é, logo, un pobo primitivo, salvaxe, ahistórico (ou o que o antropólogo Eric R. Wolf chamou "pobo sen historia») do que Cunqueiro tira material para os

8 No parágrafo do prólogo d'Os outros feirantes, que inicia tamén o limiar pouco máis extenso de Las historias gallegas de Álvaro Cunqueiro, dicía: «Este fato de retratos son continuación de outros que din fai uns anos no meu libro Xente de aquí e de acolá. Decíalle, entón, nunha carta ao Dr. Gacía-Sabell que abría o tomo, si podía ser que aquela xentińa fose a un tempo inventada por min, ou tirada da realidade, ou delambas cousas a un tempo. Eu retrataba ao minuto nunha feira, na feira galega, a esta xentińa de nós. Fíxenme tan amigo deles, que doía deixalos nun caixón da miña mesa».

No parágrafo final da carta a García-Sabell que abría Xente de aquí e de acolá (1971), escribira Cunqueiro: "quero saber de magister si ista xentiña saíume parecida no retrato, e si eu son ou non parte dela, sońándome narrador de tanta vida e miragre —e si o contar todo isto, que cáseque é de trasmundo, querse decir que eu adoito a pasar tempadas fora do mundo, esculcando? Esculcando o segredo de sere galego?». 
seus traballos humorísticos e comerciais. Moi decote, nomeadamente, nestes textos de «humor popular», Cunqueiro fixo dos galegos un mostrario: mostra monstros aos lectores de prensa coa mesma crueldade e cinismo coa que Tod Browning filmou Freaks.

\section{CRITERIOS PARA ENCADRAR O XORNALISMO DE CUNQUEIRO}

O sociólogo e tamén xornalista Robert Ezra Park escribiu no ensaio A forma de coñecemento da noticia (1940) que «as noticias, en canto forma de cońecemento, contribúen por medio do rexistro de acontecementos non só á historia e á socioloxía, senón tamén ó folclore e maila literatura; contribúen non só ás ciencias sociais, senón tamén ás humanidades». Park (1940) indicou tamén: «A función da noticia é orienta-las persoas e a sociedade no mundo actual. Na medida en que teña éxito, tende a preserva-la saúde do individuo e maila permanencia da sociedade». $\mathrm{O}$ sociólogo Park dicía que as noticias son fenómeno secular, «porén, hai tempos nos que os cambios son tan grandes e catastróficos que os individuos e os pobos xa non se interesan nos asuntos mundanos. Nese caso, a xente, vendo frustradas ambicións e esperanzas, desatende o mundo dos asuntos seculares e procura abeiro e consolo escapando do grande mundo pró mundiño da familia ou da igrexa». O xornalismo que Cunqueiro escribiu adaptándose ás miserentas restricións da ditadura franquista ten moito de fuxida do mundo. O xornalismo de Cunqueiro é, logo, sintomático de certo «estrañamento do mundo», que diría o Sloterdijk (1998), e quizais tamén de certo «kinismo popular», máis que do «cinismo da prensa», do que tamén falou Sloterdijk na Crítica da razón cínica e do que, non me ten dúbida, Cunqueiro era ben consciente.

Francisco Fernández del Riego (1981) apuntou con acerto na conclusión do artigo «A vida e a obra dun gran fabulador»: «Álvaro Cunqueiro foi un exemplo de escritor consciente no seu papel. Creou un mundo orixinal, e un sentido da existencia que puido parecer, en certo xeito, cínico e apaixonado. Atravesou os anos do "realismo a ultranza" sin variar apenas as súas raizames literarias».

No parágrafo anterior do devandito ensaio sobre a vida e a obra de Cunqueiro, escribía Del Riego: «Falando das etiquetas que lle apuñeron, manifestou en certa ocasión: "Eu fun encaselado no puro limbo, como si andivera ensimesmado 
e lonxanísimo entre arcaicas brétemas célticas. Pero ademáis escribín, e impulsei a outros a facelo, moita máis literatura social e económica que imaxinativa».

\section{A LINGUA XORNALÍSTICA DE CUNQUEIRO}

Hai quen di (Allan 1997) que os servizos telegráficos que comezaron a nutrir a prensa do século dezanove requirían unha lingua limpa da formas locais, rexionais e coloquiais. Requirían un estilo máis próximo ao da lingua científica, unha denotación estrita na que os aspectos connotativos da enunciación estivesen controlados, unha lingua atenta ao feito ${ }^{9}$. Segundo esta visión, a comunicación telegráfica levou á desaparición das formas da fala e de estilos de narración e xornalismo (a historia incrible, a mistificación, gran parte do humor, a ironía e máis a sátira) que dependían dun uso máis tradicional da lingua ${ }^{10}$. Verbo disto, tamén é importante lembrar que cada palabra dunha noticia tiña que se xustificar en termos de custo, restrición que condicionou igualmente as normas de información. Dende este punto de vista, o xornalismo de Cunqueiro foi, nos máis dos casos, e para ben da lingua, antítese do xornalismo moderno e conciso ${ }^{11}$.

De por parte, as convencións das informacións de axencia, patentes non só polo limitación á descrición de feitos e declaracións, senón tamén pola determinación rutineira das practicas do traballo informativo, fixaron no curso do século vinte a codificación da obxectividade a xeito de patrón normativo do xornalismo. Coido que, moi decote, o traballo xornalístico de Cunqueiro impugnou abertamente tales convencións».

9 Criticou a simplificación e posición ideolóxica implícita nesta concepción da lingua Kenneth Burke (1984: 175-8).

10 Porén, Anthony Smith (1996) mantén o contrario expondo o caso da confluencia da taquigrafía e máis a telegrafía no estilo das crónicas de Dickens que logo serían os Pickwick Papers, tan queridos de Cunqueiro, e do reaccionairo Augusto Assía. As técnicas non determinan inelutablemente o estilo discursivo.

11 Cunqueiro manifestou a súa conciencia lingüística moitas veces. En resposta a unha entrevista de Anxel Fole para O progreso de Lugo, en 1961, queixábase de que «en Santiago se puede estudiar árabe, pero no gallego» e engadía que «la preterización de nuestro idioma es patente». Cf. AA. VV., Álvaro Cunqueiro. Escritos recuperados. Santiago, Universidade de Santiago, 1991, p. 16. 


\section{REFERENCIAS BIBLIOGRÁFICAS}

AA. VV. (1991): Álvaro Cunqueiro. Escritos recuperados. Santiago, Universidade de Santiago.

AA. VV. (1993): Álvaro Cunqueiro. Actas do Congreso celebrado en Mondoñedo entre os días 9 e 13 de setembro de 1991. Santiago, Xunta de Galicia.

Allan, S. (1997): «News and the Public Sphere. Towards a history of impartiality and objectivity» en M. Bromley e T. O'Malley (eds.): Journalism. A reader. Londres, Routledge.

Burke, K. (1984): «Two Aspects of Speech» en Permanence and Change. Anatomy of Purpose. Berkeley, University of California Press. ( $1^{\text {a }}$ ed. 1935).

BreA, M. e J. Ma Folgar (1982): «Álvaro Cunqueiro en ABC, en 1939» en AA. VV. Homenaxe a Álvaro Cunqueiro. Santiago, Universidade de Santiago, pp. 349-369.

Cunqueiro, A. (1991): La bella del dragón. De amores, sabores y fornicios. Barcelona, Tusquets.

Cunqueiro, A. (1994): Papeles que fueron vidas. Crónicas literarias. Barcelona, Tusquets.

Cunqueiro, A. (2011): Poesía 1933-1981. Vigo, Galaxia.

Deleuze, G. e Guattari, F. (1980): Mil Plateaux. París, Minuit.

Eagleton, T. (2004): After Theory. Londres, Penguin.

Fernández del Riego, F. (1981): «A vida e a obra dun gran fabulador», Grial, no 72.

Fernández Freixanes, V. (1991): «A noticia é o miragre» en AA. VV. A nosa terra: o mundo de Cunqueiro.

Vigo, Promocións Culturais Galegas.

Lyotard, J.-F. (1973): Dérive a partir de Marx et de Freud. Paris, UGE.

Molina, C. A. (1994): «La última visita. (Entrevista a Álvaro Cunqueiro en 1981)», F. G. L. Boletín de la fundación Federico García Lorca, no 15. pp. 167-177.

PARK, R. E. (1940): «News as a form of knowledge. A chapter in the sociology of knowledge», American Journal of Sociology, vol. 45, pp. 669-686.

Pérez-Bustamante Mourier, A.-S. (1991): Las siete vidas de Álvaro Cunqueiro. Cádiz, Universidad de Cádiz.

Perucho, J. (1994): «Recuerdos de Álvaro Cunqueiro», Boletín de la Fundación Federico García Lorca, no 15, pp. 27-34.

Río Conde, E. (1993): «Álvaro Cunqueiro, colaborador da revista Vértice» en AA. VV., Álvaro Cunqueiro. Actas do Congreso celebrado en Mondoñedo entre os días 9 e 13 de setembro de 1991. Santiago, Xunta de Galicia.

SLOTERDijK, P. (1989): Crítica de la razón cínica. Madrid, Taurus (2. vols.).

SloterdijK, P. (1998): Extrañamiento del mundo. Valencia, Pre-Textos.

Smith, A. (1996): Software for the Self. Culture and Technology. Londres, Faber \& Faber.

Spitzmesser, A. M. (1995): Álvaro Cunqueiro: La fabulación del franquismo. Sada; Ediciós do Castro. 